\title{
Prevalence of Self-Reported Respiratory Symptoms, Asthma and Chronic Bronchitis in Slum Area of a Rapidly Developing Indian City
}

\author{
Bill Brashier*, Jyoti Londhe, Sapna Madas, Vandana Vincent, Sundeep Salvi \\ Chest Research Foundation (CRF), Department of Academic Research, Marigold Premises Kalyaninagar, \\ Pune, India \\ Email: "bbrashier@crfindia.com
}

Received May 15, 2012; revised June 30, 2012; accepted July 15, 2012

\begin{abstract}
Background: Poverty is an important surrogate marker for obstructive airway diseases (OAD). Slum constitutes a habitat wherein various poverty related parameters are perpetually prevalent in the ambience. 1/6th of world population lives in slums yet there is no information regarding their health status in context to asthma and COPD. Aims: We investigated the prevalence of asthma and chronic-bronchitis symptoms and associated risk-factors in slum habitats of Pune city. Methodology: 7062 adult slum-dwellers living in 12 slums of Pune city were cross-sectionally interviewed by local healthcare workers with respiratory health questionnaire which was designed using respiratory symptoms of validated European Community Respiratory Health Survey (ECRHS II) questionnaire and International Union against Tuberculosis and Lung Disease (IUATLD) bronchial symptoms questionnaire. Results: The overall prevalence of selfreported asthma symptoms was $10 \%$ (18 - 40 years: $6.5 \%$; >40 years: $13.5 \%$ ). The overall prevalence of chronic bronchitis was $8.5 \%$ [18 - 40 years: $7 \%$ (males: $7 \%$, females: $7 \%$ ); $>40$ years: $10 \%$ (males: $10 \%$, females: $10 \%$ )]. Increasing age $(p=0.00)$, female gender $(p=0.001)$, unemployment $(0.00)$ current smoking $(p=0.00)$ and ex-smoking $(p=0.004)$ emerged as significant risk factor for asthma. While, ex-smoking $(p=0.004)$ and low-education status $(p=0.00)$ emerged as significant risk factors for chronic bronchitis. Conclusion: In slums reporting of asthma and chronic-bronchitis symptoms was much higher than what has been reported earlier from India. Asthma was commonly seen in females, old age, unemployed and ever-smokers. While chronic bronchitis was commonly seen in ex-smokers and illiterate subjects. Chronic bronchitis was equally distributed amongst male and females, despite $0 \%$ prevalence of smoking in females.
\end{abstract}

Keywords: Asthma; Chronic-Bronchitis; Questionnaire; Slum-Population

\section{Introduction}

Non-communicable respiratory morbidities such as asthma and COPD are rapidly rising to emerge as leading causes of mortality worldwide. The epidemiology of asthma and COPD has consistently identified low socioeconomic status to be an important surrogate marker of the disease in world communities [1-5].

Recently there has been a sharp rise in urban settlements of poor called slums in various cities of developing countries [6,7]. This demographic trend is an outcome of rapid economic development causing migration of rural communities to urban establishments primarily in search of better livelihood. Disproportionate urbanization creates a pertinent discrepancy between provisions of basic civic amenities by infrastructure and demand in the population. Therefore many such migrants tend to live in

${ }^{*}$ Corresponding author. large separate ghettos within the cities or outskirts of cities $[6,7]$.

World health organization recognizes slum as habitat with ill-constructed overcrowded houses which lack basic civic amenities, such as adequate ventilation, sanitation and garbage disposal facilities [8]. Studies have shown that these establishments are focal points of various infectious epidemics globally [9-11]. There is also emerging evidence of high prevalence of non-infectious diseases in slums [9-11]. The slum environmental dynamics are conducive to development of obstructive airway diseases too. For example high incidence of respiratory tract infections and its transmissions [12], high indoor and outdoor air pollution [13-15], indoor-wall dampness and psychosocial stresses $[16,17]$ are typical characteristics associated with slum living conditions, and are also important risk factors associated with COPD and asthma.

Approximately 1 billion people live in slums which 
are estimated to double in next 20 years [9], with growth rate of $2 \%$ per year [6,7]. $47 \%$ of the urban population of countries in South East Asia live in slums [6,7], and constitutes $60 \%$ of the world's slum dwellers $[6,7]$. What is intriguing is that, despite such enhanced statistics of slum population globally, there is no knowledge regarding respiratory health amongst slum dwellers in context to asthma and COPD.

An estimated, 65 million people in India suffer from respiratory diseases of the non-communicable type, out of which asthma and COPD alone account for over 42 million cases, and this number is projected to grow by over $20 \%$ by the year 2030 [11]. During last few decades there has been an unprecedented growth in slum populations in the Indian subcontinent. Pune is the 7th largest developing cities of India situated in the mid-western region. It has a population of over 4 million with estimated 32\% (over 1 million) residing in slums. In last 20 years the slum population in the city has increased by $176 \%$, and similar growths have occurred in other growing cities of India [18].

This study investigated the prevalence of asthma and chronic bronchitis amongst the slum dwellers of Pune city and risk-factors associated with them using a respiratory-health questionnaire.

\section{Study Design}

This was a cross-sectional, interviewer administered, questionnaire based survey in which slum population living in 12 slums of Pune city was interviewed by local healthcare workers with previously validated respiratory health questionnaire.

\section{Study Site and Population}

There are 353 registered and 211 unregistered slums distributed in 14 ward regions of Pune City. Amongst these wards we identified Yerwada ward-region as our primary study site. This ward constitutes 63 slums with over 70,000 population. We have been conducting monthly respiratory health clinics in 54 of the 63 slums and are known as healthcare providers in the community. These slums are one of the most densely populated in the Pune city, with extreme squalor conditions and lack of provisions of basic civic-amenities such as electricity, sanitation and water supply [18].

In these slums there were 13 local health workers who were primarily employed in imparting child and maternal care in the community. Each health worker catered responsibility of at least 4 slums, and had close rapport with the slum population [19]. We approached all 13 health workers, but only three volunteered to conduct field interviews for this survey. Therefore we limited our study to only 12 slums which were under the work pro- file of the three selected healthcare workers. We selected all subjects $\geq 18$ years living in these slums as our study population.

\section{Study Questionnaire}

We designed a respiratory health questionnaire using European Community Respiratory Health Survey (ECRHS II) questionnaire [20] and International Union against Tuberculosis and Lung Disease (IUATLD) bronchial symptoms questionnaire [21]. These questions have been used to identify asthma and chronic-bronchitis in earlier studies in India [22-24] and have also been validated in Indian community. Additional questions related to riskfactors such as age, area of the house, overcrowding, annual income, gender, pets and livestock at home, type of house, employment, education, fuel used for cooking, presence of separate kitchen, smoking status and history of tuberculosis were also asked. All questions were translated into two local languages (Hindi and Marathi) and back translated to ensure quality of translations.

According to questionnaire asthma was identified in two ways: firstly, if subject was ever diagnosed as asthma or had an attack of asthma or had treatment of asthma in his/her lifetime. Secondly, asthma was also identified as presence of cough or breathlessness along with at least one of the following asthma specific symptoms: 1) Wheeze without cold; 2) Episodes of waking up with chesttightness first thing in the morning without cold; 3) Episodes of waking up in the night with cough, wheezing and shortness of breath without cold. On the other hand chronic bronchitis was defined as presence of "cough on most days for as much as three months each year during the previous 2 years, which was associated with phlegm that was more than usual" $[20,21,24,25]$.

\section{Study Methods}

Each health worker was imparted optimal training in conduct of interviews with respiratory-health questionnaire before the beginning of the survey. To maintain the quality of the interviews the research staff members accompanied the field workers during the home visits. A satisfactory competency of interview was defined as more than $90 \%$ questions answered according to the ECRHS guidelines. Once this competency was achieved in more than 3 consecutive interviews for 3 different study subjects, the healthcare workers were allowed to conduct independent surveys. Every house in the selected slums was approached and all adult subjects living in these homes were invited to participate. The visits were made at time most convenient to the families. Maximum of three attempts were made to meet the subjects who were not present during the first visit before dropping the subject from the study. 
The interviewed questionnaires were reviewed weekly by the study coordinator. The study coordinator also randomly visited $10 \%$ slum homes every week and readministered the same questionnaire to verify the interview responses to ensure quality of the data.

The study subjects were categorized as young adults which include ages between $18-40$ years and elderly (COPD target population) $>40$ years. A prior written informed consent was obtained from each study subject. The study was approved by the institutional ethics committee (approval no. CRF/22/OT).

\section{Statistics}

Prevalence rates of self-reported respiratory symptoms and asthma and COPD symptoms were defined using descriptive statistics. The association was studied in two step model. In first step Chi-square test was used to study associations between prevalence of asthma and chronicbronchitis and risk-factor variables, such as age, gender, livestock at home, type of house, employment, education, fuel used for cooking, separate kitchen and smoking status. In second step, the significant risk factors variables identified in the first step were adjusted in logistic regression to identify independent associations. The strengths of these associations were measured using odds ratio (OR) with $5 \%$ alpha error and $95 \%$ confidence intervals.

\section{Results}

The field workers visited a total of 2634 homes within the 12 slums, constituting 8437 adult slum residents. A total of 806 were unavailable for interviews, 351 subjects refused consent and 87 gave incomplete interviews. A total of 131 interviews were rejected during cross verification by the study coordinator. Therefore there were 7062 completed questionnaire interviews which were finally used for data analysis. This included 5041 subjects of 18 - 40 years of age ( $49 \%$ males; $51 \%$ females) and $2021>40$ years of age (51\% males; $49 \%$ females) (Table 1, Figure 1).

\section{Prevalence of Self-Reported Asthma and Symptoms of Chronic Bronchitis}

The overall prevalence of asthma in adult slum population was $10 \%$. The prevalence of asthma defined as ever had asthma, treatment of asthma or asthma attack was $2.15 \%$, while prevalence asthma defined with symptoms was $7.85 \%$. In the age groups of $18-40$ years the prevalence of asthma was $6.5 \%$ ( $6 \%$ males; $7 \%$ females) and $>$ 40 years was $13.5 \%$ ( $11 \%$ males; $16 \%$ females). In age groups $>40$ years asthma symptoms were significantly higher in females than males $(\mathrm{p}=0.001)$ (Figure 2 and
Table 2).

The overall prevalence of self-reported symptoms of chronic bronchitis was $8.5 \%$ in slum adult population, which included 7\% (7\% males and 7\% females) amongst age groups 18 - 40 years, and $10 \%(10 \%$ males; $10 \%$ females) amongst $>40$ years. In elderly subjects with chronic bronchitis 58\% males and 100\% females had never smoked (Table 2).

\section{Factors Associated with Self Reported Symptoms of Asthma}

Increasing age (OR: 3.31 ; CI: $2.36,4.63$ for ages $>55$ years of age $p=0.00)$, female gender (OR: 1.43 ; CI: 1.15 , $1.79, \mathrm{p}=0.001)$, unemployment (OR: 1.38; CI: 1.12, 1.69, $\mathrm{p}=0.00$ ), ex-smoking (OR: 2.54; CI: 1.34, 4.80, $\mathrm{p}=0.004)$ and current smoking (OR: 2.29; CI: 1.71, 3.07, $\mathrm{p}=0.00$ ) emerged as significant independent risk factors for self

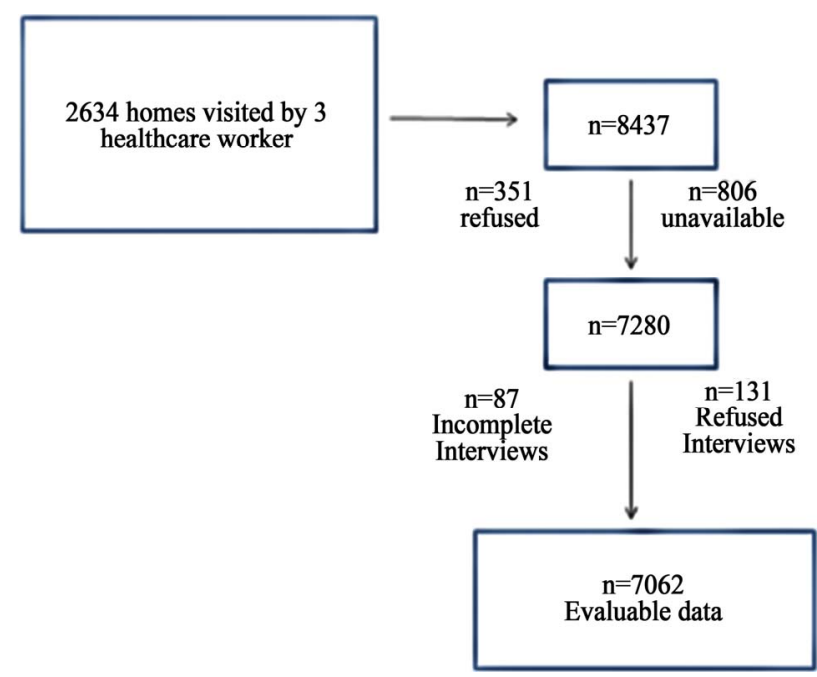

Figure 1. Flow chart of study events.

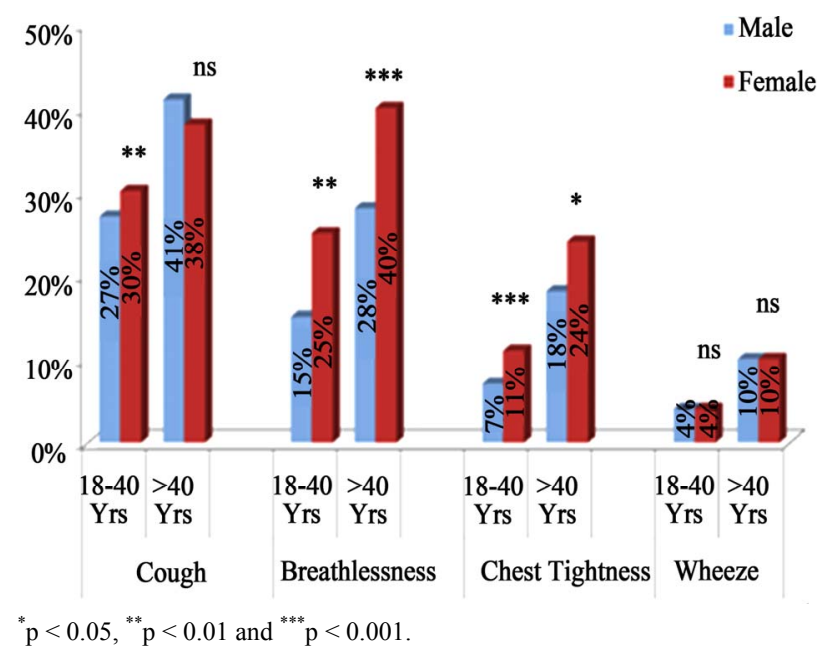

Figure 2. Age and gender wise prevalence of respiratory symptoms in overallslum population. 
Table 1. Population demographics of 7062 adult slum dwellers.

\begin{tabular}{|c|c|c|c|c|}
\hline \multirow{2}{*}{ Variable } & \multicolumn{2}{|c|}{18 - 40 Years } & \multicolumn{2}{|c|}{$>40$ Years } \\
\hline & Frequency & $\%$ & Frequency & $\%$ \\
\hline \multicolumn{5}{|l|}{ Sex } \\
\hline Male & 2489 & $49.40 \%$ & 1026 & $50.80 \%$ \\
\hline Female & 2552 & $50.60 \%$ & 995 & $49.20 \%$ \\
\hline \multicolumn{5}{|l|}{ Occupation } \\
\hline Employed & 817 & $16.20 \%$ & 328 & $16.30 \%$ \\
\hline Self-Employed & 1977 & $39.30 \%$ & 616 & $30.60 \%$ \\
\hline Unemployed & 2239 & $44.50 \%$ & 1068 & $53.10 \%$ \\
\hline \multicolumn{5}{|l|}{ Education } \\
\hline Postgraduate & 80 & $1.60 \%$ & 13 & $0.60 \%$ \\
\hline Graduate & 466 & $9.20 \%$ & 45 & $2.20 \%$ \\
\hline Secondary & 2615 & $51.90 \%$ & 539 & $26.70 \%$ \\
\hline Primary & 1062 & $21.10 \%$ & 485 & $24.00 \%$ \\
\hline Uneducated & 815 & $16.20 \%$ & 938 & $46.40 \%$ \\
\hline \multicolumn{5}{|l|}{ Smoking Status } \\
\hline Non-Smoker & 4772 & $94.70 \%$ & 1683 & $83.30 \%$ \\
\hline Ex-Smoker & 30 & $0.60 \%$ & 41 & $2.00 \%$ \\
\hline Current Smoker & 239 & $4.70 \%$ & 296 & $14.07 \%$ \\
\hline \multicolumn{5}{|l|}{ Fuel for Cooking } \\
\hline Liquefied Petroleum Gas & 3656 & $73.90 \%$ & 1522 & $75.70 \%$ \\
\hline Kerosene & 1065 & $21.30 \%$ & 375 & $18.70 \%$ \\
\hline Biomass & 227 & $4.50 \%$ & 94 & $4.70 \%$ \\
\hline Mixed & 51 & $1.00 \%$ & 19 & $0.90 \%$ \\
\hline \multicolumn{5}{|l|}{ Separate Kitchen } \\
\hline Yes & 1868 & 37.3 & 856 & $42.60 \%$ \\
\hline No & 3136 & $62.70 \%$ & 1155 & $57.40 \%$ \\
\hline \multicolumn{5}{|l|}{ Annual Income (in Dollars) } \\
\hline$>1000$ & 7 & $0.1 \%$ & & \\
\hline $200-1000$ & 4849 & $96.8 \%$ & 1955 & $97.20 \%$ \\
\hline$<200$ & 151 & $3.0 \%$ & 56 & $2.80 \%$ \\
\hline \multicolumn{5}{|l|}{ Type of House } \\
\hline Concrete & 2691 & $53.7 \%$ & 1147 & $57.00 \%$ \\
\hline non-Concrete & 2320 & $46.3 \%$ & 865 & $43.00 \%$ \\
\hline \multicolumn{5}{|l|}{ Livestock at Home } \\
\hline Yes & 202 & $4.0 \%$ & 92 & $4.60 \%$ \\
\hline No & 4797 & $96.0 \%$ & 1914 & $95.40 \%$ \\
\hline
\end{tabular}

Table 2. Prevalance rates of self reported asthma and self reported chronic bronchitis in slum dults $(\mathbf{n}=7062)$.

\begin{tabular}{|c|c|c|c|c|c|c|c|c|c|}
\hline \multirow[t]{2}{*}{ Variable } & \multicolumn{3}{|c|}{$18-40$ Years $(n=5041)$} & \multicolumn{3}{|c|}{$>40$ Years $(n=2021)$} & \multicolumn{3}{|c|}{$\begin{array}{c}18-40 \text { Years } \\
\text { Versus }>40 \text { Years }\end{array}$} \\
\hline & Overall & Male & Female & p-Value & Overall & Male & Female & p-Value & p-Value \\
\hline $\begin{array}{c}{ }^{*} \text { Self Reported } \\
\text { Asthma }\end{array}$ & $7 \%$ & $6 \%$ & $7 \%$ & ns & $13 \%$ & $11 \%$ & $16 \%$ & $<0.001$ & $<0.001$ \\
\hline $\begin{array}{c}\text { *Self Reported } \\
\text { Chronic Bronchitis }\end{array}$ & $7 \%$ & $7 \%$ & $7 \%$ & $\mathrm{~ns}$ & $10 \%$ & $10 \%$ & $10 \%$ & ns & $<0.001$ \\
\hline
\end{tabular}

According to study definition; $\mathrm{ns}=\mathrm{p}>0.05$. 
reported asthma in the slum population. Illiteracy showed significant association with asthma initially but its effect disappeared on adjustment with other risk factor variables (Table 3).

\section{Factors Associated with Self Reported Symptoms of Chronic Bronchitis}

Low education status (OR: 1.39; CI: 1.07, 1.80, $\mathrm{p}=0.00$ ) and exsmoking (OR: 1.65, CI: 1.21, 2.24, $\mathrm{p}=0.04$ ) emerged as significant risk factor for chronic bronchitis in slum population. Increasing age and usage of kerosene fuel for cooking showed significant association with chronic bronchitis initially, however, its effect disappeared on adjustment with other risk factors (Table 4).

Type of occupation, fuel, having separate kitchen, livestock at home, past history of tuberculosis and type of house did not show any association with symptoms of asthma and chronic bronchitis.

Table 3. Risk factor associations with self reported Asthma in slum adult population $(\mathrm{n}=\mathbf{7 0 6 2})$.

\begin{tabular}{|c|c|c|c|}
\hline & Variable & Unadjusted OR (95\% CI) & Adjusted $^{+} \mathrm{OR}(95 \% \mathrm{CI})$ \\
\hline \multirow{5}{*}{ Age } & 18 - 25 Years & & \\
\hline & 25 to 35 Years & $1.88(1.43,2.47)^{* *}$ & $1.96(1.48,2.58)^{* *}$ \\
\hline & 35 - 45 Years & $2.44(1.84,3.25)^{* *}$ & $2.37(1.75,3.20)^{* *}$ \\
\hline & 45 to 55 Years & $3.44(2.52,2.70)^{* *}$ & $3.09(2.22,4.29)^{* *}$ \\
\hline & Above 55 Years & $4.13(3.04,5.61)^{* *}$ & $3.31(2.36,4.63)^{* *}$ \\
\hline \multirow[b]{2}{*}{ Employment } & $\begin{array}{l}\text { Male vs. } \\
\text { Female }\end{array}$ & $1.34(1.13,1.58)^{* *}$ & $1.43(1.15,1.79)^{* *}$ \\
\hline & $\begin{array}{l}\text { Employed } \\
\text { Unemployed }\end{array}$ & $1.46(1.23,1.72)^{* *}$ & $1.38(1.12,1.69)^{* *}$ \\
\hline \multirow{4}{*}{ Education } & Graduate/PG & & \\
\hline & Secondary & $1.19(0.82,1.74)$ & $1.01(0.69,1.49)$ \\
\hline & Primary & $1.48(0.99,2.21)^{*}$ & $1.08(0.72,1.62)$ \\
\hline & Uneducated & $2.18(1.49,3.20)^{* *}$ & $0.89(0.59,1.36)$ \\
\hline \multirow{3}{*}{ Smoking } & Non-Smoker & & \\
\hline & Ex-Smoker & $2.62(1.36,4.96)^{* *}$ & $2.54(1.34,4.80)^{* *}$ \\
\hline & Smoker & $2.08(1.61,2.70)^{* *}$ & $2.29(1.71,3.07)^{* *}$ \\
\hline \multirow{3}{*}{ Fuel for Cooking } & Liquefied Petroleum Gas & & \\
\hline & Kerosene & $1.05(0.85,1.30)$ & $0.98(0.78,1.23)$ \\
\hline & Biomass & $1.08(0.71,1.63)$ & $1.01(0.66,1.52)$ \\
\hline Separate Kitchen & $\begin{array}{l}\text { No } \\
\text { Yes. }\end{array}$ & $0.88(0.74,1.04)$ & $0.88(0.73,1.07)$ \\
\hline Type of House & $\begin{array}{l}\text { Non-Concrete } \\
\text { Concrete }\end{array}$ & $1.09(0.93,1.30)$ & $1.14(0.95,1.37)$ \\
\hline Livestock at Home & $\begin{array}{l}\text { Yes } \\
\text { No }\end{array}$ & $1.08(0.72,1.62)$ & $0.78(0.49,1.23)$ \\
\hline
\end{tabular}

${ }^{+}$Adjusted for: Age, sex, employment status, education status and smoking status, ${ }^{*}=\mathrm{p}<0.05,{ }^{* *}=\mathrm{p}<0.01$. 
Table 4. Risk factor associations with self reported symptoms of chronic bronchitis in slum adult population $(\mathrm{n}=\mathbf{7 0 6 2})$.

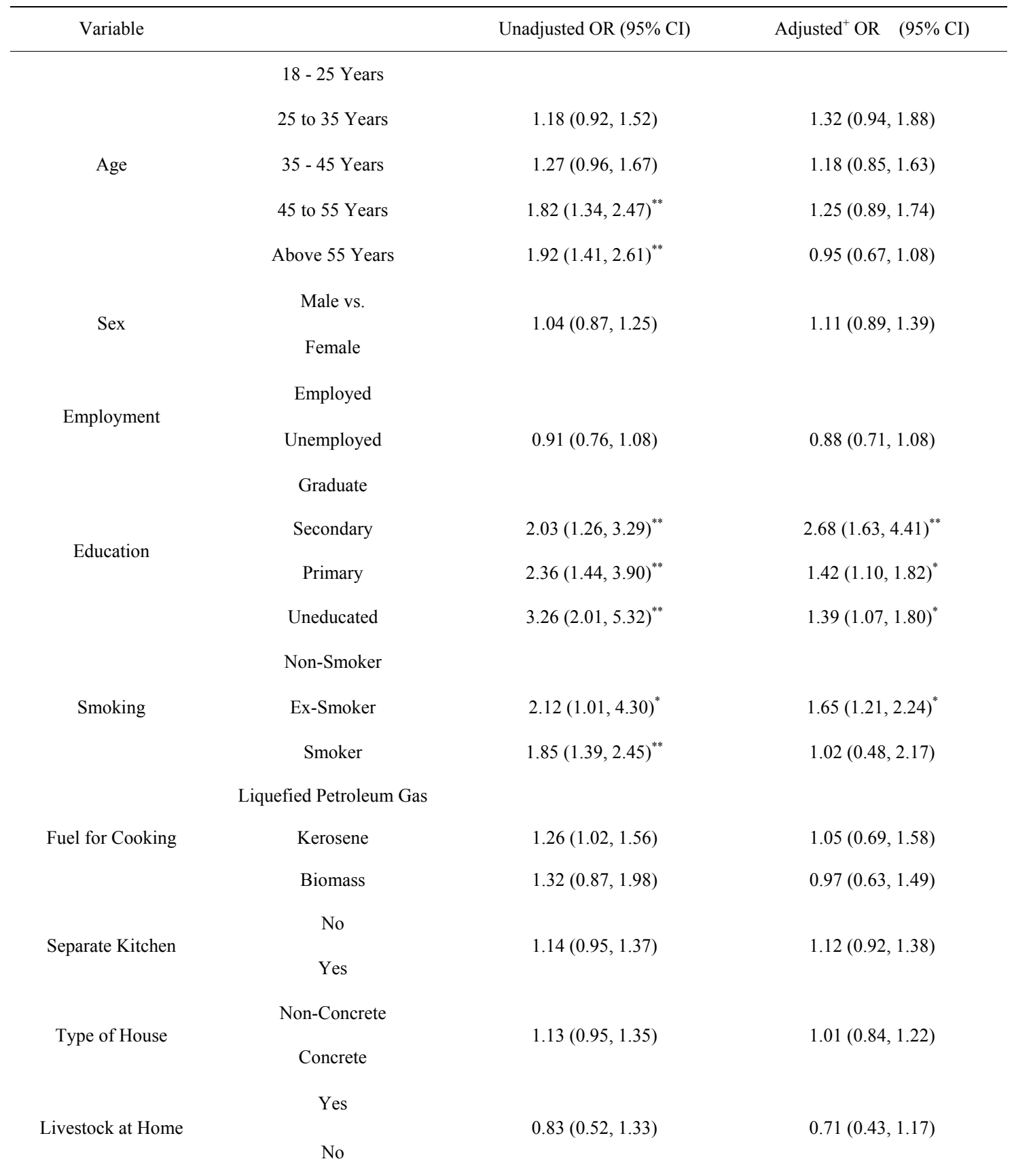

${ }^{+}$Adjusted for: Age, smoking status, education status, ${ }^{*}=\mathrm{p}<0.05,{ }^{* *}=\mathrm{p}<0.01$.

\section{Discussion}

This is the first study which has investigated the prevalence of respiratory symptoms in context to asthma and chronic-bronchitis in more than 7000 adult slum dwellers, and has shown high prevalence of these respiratory morbidities in the slum community. Female gender, increasing age, unemployment and smoking history were significant risk factors associated with asthma in the slum dwellers. While, only smoking and low education status emerged as significant risk factors associated with symptoms of chronic bronchitis. There was no association of exposures to unhealthy fuels with either asthma or chronic bronchitis in the slum population.

This study reported high prevalence of asthma (10\%) in the slum population, which was much higher than what has been reported before from the Indian subcontinent $[22,23]$. We could identify only one asthma prevalence study by Aggarwal et al. which had a comparable 
study methodology as our research [23]. This study had shown that the prevalence of asthma in four major cities of India ranged between $1.7 \%-3.5 \%$, and has emerged as backbone of asthma epidemiology in India. However, Aggarwal et al. defined asthma as subject ever diagnosed as asthma or received treatment of asthma or had an exacerbation of asthma. Although a part of our definition of asthma was similar to Aggarwal et al., we also included additional symptomatic definition of the disease which was derived from various asthma epidemiological studies $[20,21]$. We assume that relying only on physician diagnosis of asthma in an epidemiological surveys, although specific, can induce a risk of underestimating a disease in community especially when there is poor understanding of a disease even at the physician level [26]. This could be the reason of low prevalence reported in study by Aggarwal et al., and has falsely placed India in low asthma prevalence zone globally. Additionally, we also assume that because of poor access to healthcare facilities associated with slum population [27], there could have been increased probability of generating falsely low asthma prevalence rates if our study had depended only on criteria of physician diagnosis of asthma.

Further, we cannot totally attribute high prevalence of asthma in slums only to different asthma definitions. There is enough evidence to suggest that asthma is more common amongst economically deprived, the reasons for which have been unclear. Wright et al. [1] has suggested that this association could have an ecological dimensions such as disproportionate exposures to air pollution, indoor wall dampness and indoor allergens, and psychosocial stresses related to poor housing conditions.

Our study has also shown that prevalence of self reported symptoms of chronic bronchitis in slum population of ages $18-40$ years was $7 \%$, while prevalence of chronic bronchitis in age group $>40$ years was $10 \%$, which is higher than what has been reported before from India. The question to capture chronic bronchitis was based on a standard IUTALD and ECRHS questionnaire definitions, which have been used in various studies before [20,21,24], and has been instrumental in studying prevalence of chronic bronchitis globally. In addition, Indian prevalence of COPD is primarily attributed to symptoms of chronic bronchitis and not spirometry [24]. Jindal et al. [24] has shown that prevalence of chronic bronchitis in 4 major cities from different geographical locations of India to be $4.1 \%$ in subjects $>35$ years of age. Mahesh et al. [25] has shown prevalence of chronic cough for at-least 3 months to be $7.7 \%$ and sputum production for at-least 3 months to be $7.5 \%$ in rural population of India $>40$ years of age. Symptoms of chronic cough with sputum production entails chronic inflammatory processes in the lungs which evokes varied differential diagnosis such as recurrent respiratory tract infec- tions, COPD, asthma, bronchioectasis and cardiac failure. Nevertheless chronic bronchitis has been attributed as established early predictor of COPD and accelerated lung function decline $[28,29]$.

The risk factors associated with asthma such as increasing age, female gender and smoking, and risk factors associated with chronic bronchitis such as smoking and illiteracy are not novel [30,31]. Similar observations have been noted in various other studies before. However, our study could not show any association of chronic bronchitis with male gender, despite $0 \%$ prevalence smoking in females and $17 \%$ prevalence smoking in males. Current evidence suggests that male gender is a potential risk factor for chronic bronchitis, fundamentally because of relatively high prevalence of smoking amongst males $[28,32]$. What was further intriguing was that, even exposure to biomass fuel smoke which has been regarded as important risk factor for respiratory morbidities [33] did not contribute to chronic bronchitis in slum women. This suggests a possibility of alternative environmental triggers in the slum ambience which compels further probing. This study also showed that only $5 \%$ homes in the slums were currently using unhealthy fuels for domestic purposes, indicating a positive trend towards reducing risk factor exposures amongst urban poor. This also implies, that in future biomass smoke may not remain a risk factor for morbidities such as obstructive airway diseases in urban settings. However, there is a potential of emergence of new phenotype of obstructive airway disease related to poor environmental conditions, with focal point in slum habitats.

Another interesting finding in this study was absence of association between chronic bronchitis and increasing age. This is contradictory to what has been observed before. Studies have shown that prevalence of chronic bronchitis is positively related to age $[28,29,32]$, which has been attributed to changes in immune system and negative impact of age on lung physiology. One approximate explanation to the contrary observations in our study could be, that exposures to adverse slum environmental dynamics [1,5] may trigger recurrent induction of immune processes in lungs of slum residents which could compromise lung growth during developmental stages such as childhood [34]. This may result in low lung volumes and related disease processes in early adulthood, hence, negating the age effect on diseases such as COPD and chronic bronchitis. However, in this study we did not capture durational history of slum residence, therefore could not investigate role of childhood lived in slums.

An additional determinant that emerged as significant risk factor of asthma in the slum population was unemployment status. This association was however difficult to explain. Not having a job cues towards more time spent at home, therefore more exposure to slum envi- 
ronmental dynamics. However, it could also be argued that because of asthma symptoms subjects were not going to work and staying at homes. Nevertheless unemployment has been associated to emotional stresses [35], and emotional disturbances are known to induce allergic immune mechanisms [17].

The two major limitations of this study were; firstly that, although, conducted in al large population size, was limited to only 12 slums from a city, therefore, these findings may lack generalization. Secondly, we did not validate the respiratory health questionnaire in slum population, however, these questionnaires are already been validated in Indian population in prior studies. Here it is important to mention that sensitive populations, such as slums, may have pertinent communication barriers related to discussing health status to alien organizations during health surveys, primarily due to fear of losing sources of livelihood. This analogously creates risk of generating spurious information. Therefore we limited our study site to slums where we were already known, and had general acceptance in the community. Further, the field workers were themselves from the slum community, and we had localized this study to only those slums which were under medical jurisdiction of the three health workers.

The inference of this survey is that, there is an epidemic of asthma and COPD related respiratory symptoms in the slum community, which is likely to remain unidentified. In era when diseases such as asthma and COPD are rapidly rising to be leading killers globally, the increasing slum population will potentially add to the burden of these diseases in the countries where urban slum habitats constitute sizeable population. This study also cues towards the need of conducting separate asthma and COPD prevalence studies in slums to reveal actual burden of these diseases in global community, which are assumedly tip of the iceberg. There is also an urgent need for regularization of urbanization and slum formations in the cities in order to control asthma and COPD morbidities globally.

\section{Acknowledgements}

We thank the families who participated in this project and gratefully acknowledge Mrs Shailija Jagtap. Mrs Mangala Dalvi and Mrs Chaya Gaware for their assistance in data collection. We also Thank Dr Rahul Kodgule for helping us to write this manuscript. This study was funded by Cipla pharmaceutical Ltd.

\section{REFERENCES}

[1] R. J. Wright and S. V. Subramanian. "Advancing Multi Level Framework for Epidemiologic Research on Asthma Disparities," Chest, Vol. 132, No., 2007, pp. 757S-769S.

\section{doi:10.1378/chest.07-1904}

[2] J. M. Anto, P. Vermeire, J. Vestbo, et al., "Epidemiology of Chronic Obstructive Pulmonary Disease," European Respiratory Journal, Vol. 17, No. 5, 2001, pp. 982-994. doi:10.1183/09031936.01.17509820

[3] S. Shohaimi, A. Welch, S. Bingham, et al., "Area Deprivation Predicts Lung Function Independently of Education and Social Class," European Respiratory Journal, Vol. 24, No. 1, 2004, pp. 157-161. doi:10.1183/09031936.04.00088303

[4] D. A. Lawlor, S. Ebrahim and S. G. Davey, "Association between Self-Reported Childhood Socioeconomic Position and Adult Lung Function: Findings from the British Women's Heart and Health Study," Thorax, Vol. 59, No. 3, 2004, pp. 199-203. doi:10.1136/thorax.2003.008482

[5] D. M. Mannino and A. S. Buist, "Global Burden of COPD: Risk Factor Prevalence, and Future Trends," Lancet, Vol. 370, No. 9589, 2007, pp. 765-773. doi:10.1016/S0140-6736(07)61380-4

[6] G. L. Ooi and K. H. Phua, "Urbanization and Slum Formation," Journal of Urban Health, Vol. 84, No. 1, 2007, pp. 27-34. doi:10.1007/s11524-007-9167-5

[7] E. D. Sclar, P. Garau and G. Carolini, "The 21st Century Health Challenge of Slums and Cities," Lancet, Vol. 365, No. 9462, 2005, pp. 901-903.

doi:10.1016/S0140-6736(05)71049-7

[8] United Nations Settlement Programe (UN-HABITAT), "State of World Cities," 2006/2007. www.unhabitat.org.SOWC/06/07/13/slum2

[9] A. Unger and L. W. Riley, "Slum Health: From Understanding to Action (Essay)," PLoS Medicine, Vol. 4, No. 10, 2007, pp. 1561-1566.

[10] L. W. Riley, A. I. Ko, A. Unger, et al., "Slum Health: Diseases of Neglected Populations," BMC International Health and Human Rights, Vol. 7, 2007, p. 2. doi:10.1186/1472-698X-7-2

[11] B. Nongkynrih, B. K. Patro and C. S. Pandav, "Current Status of Communicable and Non-Communicable Diseases in India," Journal of Association of Physicians in India, Vol. 52, 2004, pp. 118-123.

[12] J. E. Gern, L. A. Rosenthal, R. L. Sorkness and R. F. Lemanske Jr., "Effects of Viral Respiratory Infections on Lung Development and Childhood Asthma," Journal of Allergy and Clinical Immunology, Vol. 115, No. 4, 2005, pp. 668-674. doi:10.1016/j.jaci.2005.01.057

[13] N. Bruce, R. Perez-Padilla and R. Albalak, "Indoor Air Pollution in Developing Countries: A Major Environmental and Public Health challenge," Bulletin of the World Health Organization, Vol. 78, No. 9, 2000, pp. 1078-1092.

[14] P. Kulshreshtha, M. Khare and P. Seetharaman, "Indoor Air Quality Assessment in and around Urban Slums of Delhi City, India," Indoor Air, Vol. 18, No. 6, 2008, pp. 488-498. doi:10.1111/j.1600-0668.2008.00550.x

[15] B. Brunekreef, R. Beelen, G. Hoek, et al., "Effects of Long-Term Exposure to Traffic-Related Air Pollution on Respiratory and Cardiovascular Mortality in the Netherlands: The NLCS-AIR Study," Research Report (Health 
Effects Institute), Vol. 139, 2009, pp. 5-71, 73-89.

[16] A. L. Kozyrskyj, G. E. Kendall, P. Jacoby, et al., "Association between Socioeconomic Status and the Development of Asthma: Analyses of Income Trajectories," American Journal of Public Health, Vol. 100, No. 3, 2010, pp. 540-546. doi:10.2105/AJPH.2008.150771

[17] R. J. Wright, "Stress and Atopic Disorders," Journal of Allergy and Clinical Immunology, Vol. 116, 2005, pp. 1301-1306. doi:10.1016/j.jaci.2005.09.050

[18] S. Sen, J. Hobson and P. Joshi, "The Pune Slum Census: Creating a Socio-Economic and Spatial Information Base on a GIS for Integrated and Inclusive City Development," Habitat International, Vol. 27, No. 4, 2003, pp. 595-611. doi:10.1016/S0197-3975(03)00007-9

[19] Department of Women and Child Development, Ministry of Human Resources Development, "Report: Government of India Integrated Child Development Services," New Dehli, 1995, pp. 1-24.

[20] P. G. Burney and D. Jarvis, "The European Community Respiratory Health Survey II (ECRHS II),” 2002. www.ecrhs.org

[21] P. G. Burney, L. A. Laitinen, S. Perdrizet, et al., "Validity and Repeatability of the IUATLD (1984) Bronchial Symptoms Questionnaire: An International Comparison," European Respiratory Journal, Vol. 2, No. 10, 1989, pp. 940-945.

[22] R. V. Chowgule, V. M. Shetye, J. R. Parmar, et al., "Prevalence of Respiratory Symptoms, Bronchial Hyperreactivity, and Asthma in a Mega City. Results of the European Community Respiratory Health Survey in Mumbai (Bombay)," American Journal of Respiratory and Critical Care Medicine, Vol. 158, 1998, pp. 547-554.

[23] A. N. Aggarwal, K. Chaudhry, S. K. Chhabra, et al., "Prevalence and Risk Factors for Bronchial Asthma in Indian Adults: A Multi-Centre Study," Indian Journal of Chest Disease and Allied Sciences, Vol. 48, 2006, pp. 13-22.

[24] S. K. Jindal, A. N. Aggarwal, K. Chaudhry, et al., "Asthma Epidemiology Study Group. A Multicentric Study on Epidemiology of Chronic Obstructive Pulmonary Disease and Its Relationship with Tobacco Smoking and Environmental Tobacco Smoke Exposure," Indian Journal of Chest Disease and Allied Sciences, Vol. 48, 2006, pp. 23-27.

[25] P. A. Mahesh, B. S. Jayraj, S. T. Prahlad, et al., "Validation of Structured Questionnaire for COPD and Prevalence of COPD in Rural Area of Mysore: A Pilot Study," Lung India, Vol. 26, No. 3, 2009, pp. 63-69. doi:10.4103/0970-2113.53226

[26] A. Kotwani, S. K. Chhabra, V. Tayal, et al., "Quality of Asthma Management in Urban Community in Delhi, In- dia," Indian Journal of Medical Research, Vol. 135, No. 20, 2012, pp. 184-192.

[27] A. Banerjee, J. S. Bhawalkar, S. L. Jadhav, et al., "Access to Health Services among Slum Dwellers in an Industrial Township and Surrounding Rural Areas: A Rapid Epidemiological Assessment," Journal of Family Medicine and Primary Care, Vol. 1, No. 1, 2012, pp. 20-26.

[28] G. J. Huchon, A. Vergnenegre, F. Neukirch, et al., "Chronic Bronchitis among French Adults: High Prevalence and under Diagnosis," European Respiratory Journal, Vol. 20, 2002, pp. 806-812. doi:10.1183/09031936.02.00042002

[29] R. E. Kanner, N. R. Anthonisen and J. E. Connett, "Lower Respiratory Illnesses Promote $\mathrm{FEV}_{1}$ Decline in Current Smokers But Not Ex-Smokers with Mild Chronic Obstructive Pulmonary Disease: Results from the Lung Health Study," American Journal of Respiratory and Critical Care Medicine, Vol. 164, 2001, pp. 358-364.

[30] M. Masoli, D. Fabian, S. Holt, et al., "Global Initiative for Asthma (GINA) program: The Global Burden of Asthma: Executive Summary of the GINA Dissemination Committee Report," Allergy, Vol. 59, 2004, pp. 469-478. doi:10.1111/j.1398-9995.2004.00526.x

[31] R. A. Pauwels, A. S. Buist, P. M. Calverley, et al., "The GOLD Scientific Committee. Global Strategy for the Diagnosis, Management, and Prevention of Chronic Obstructive Pulmonary Disease. NHLBI/ WHO Global Initiative for Chronic Obstructive Lung Disease (GOLD) Workshop Summary," American Journal of Respiratory and Critical Care Medicine, Vol. 163, 2001, pp. 12561276.

[32] L. E. Loschmann, J. Sunyer, E. Plana, et al., "Socioeconomic Status, Asthma and Chronic Bronchitis in a Large Community-Based Study," European Respiratory Journal, Vol. 29, 2007, pp. 897-905. doi:10.1183/09031936.00101606

[33] S. Liu, Y. Zhou, X. Wang, et al., "Biomass Fuels Are the Probable Risk Factor for Chronic Obstructive Pulmonary Disease in Rural South China," Thorax, Vol. 62, No. 10, 2007, pp. 889-897. doi:10.1136/thx.2006.061457

[34] S. O. Shaheen, D. J. P. Barker and S. T. Holgate, "Do Lower Respiratory Tract Infections in Early Childhood Cause Chronic Obstructive Pulmonary Disease?" American Journal of Critical Care Medicine, Vol. 151, No. 5, 1995, pp. 1649-1652.

[35] N. Kawakami, E. A. Abdulghani, J. Alonso, et al., "EarlyLife Mental Disorders and Adult Household Income in the World Mental Health Surveys," Biological Psychiatry, Vol. 72, No. 3, 2012, pp. 228-237. doi:10.1016/j.biopsych.2012.03.009 